Article

\title{
Impacts of Green Production Decision on Social Welfare
}

\author{
Zheng Zhang ${ }^{1}$, Yingtong Wang ${ }^{1}$, Qingchun Meng ${ }^{1, *}$ and Xinyang Luan ${ }^{2}$ \\ 1 School of Management, Shandong University, Jinan 250100, China; zzstu-86@163.com (Z.Z.); \\ 201712687@mail.sdu.edu.cn (Y.W.) \\ 2 Shandong Finance Group, Jinan 250002, China; lxydtc@163.com \\ * Correspondence: meqich@sdu.edu.cn
}

Received: 9 December 2018; Accepted: 12 January 2019; Published: 16 January 2019

\begin{abstract}
As an important approach of achieving sustainable development, green production plays a significant role in improving the ecological environment and total social welfare. In order to clarify the impacts of green production on social welfare favorably, this paper assumes that there are two types of consumers in the market: the green and the brown. Green consumers have green preference, focusing on the environmental and physical attributes of products; while brown consumers only value the physical attributes. We have obtained some intriguing conclusions through the use of the Hotelling model, as follows: (i) The total social welfare will benefit from green production. Meanwhile, we also find that the social welfare is likely to reach the highest value in scenario BG (i.e., both enterprises implement green production) or scenario SG (i.e., only one enterprise implements green production). (ii) Moreover, the total social welfare is always positively related to the degree of consumer green preference and unit of environmental benefit parameters in scenario SG and scenario BG. (iii) Finally, in scenario BG, the proportion of green consumers has a positive effect on the total social welfare, while only when certain conditions are satisfied, the higher proportion of green consumers will benefit the social welfare in scenario SG. Our findings can provide useful managerial insights for policy-makers in the development of green production.
\end{abstract}

Keywords: green production; social welfare; Hotelling model; heterogeneous consumers

\section{Introduction}

As economy and society develop, green production has attracted wide attention from all circles of the society [1]. For instance, many conferences with the theme of 'green' or 'sustainable' have been held around the world, such as the United Nations Summit on Sustainable Development 2015, Rio +20 Summit, International Conference on Sustainable Development 2018, and others [2,3]. The significance of green and sustainable development is stressed at these conferences. More and more international companies have started focusing on green production, and have put the concepts of green production into their strategic plans and daily production operations. For example, IKEA emphasizes environmental protection and sustainability in its production process of green product [4]; General Motors has integrated the concept of green manufacturing into R\&D, manufacturing, procurement, and service, which lays a foundation for its sustainable development [5]; companies such as H\&M, Marks \& Spencer, and Levi's all use new technologies in their production processes to reduce carbon emissions and achieve green production [6]. Interestingly, different countries have different attitudes towards green production. Developed economies in the world, such as the United States, the European Union (EU), Japan, etc., have taken various measures to encourage the development of green economy and formulate green development strategy [7-10]. In the China Africa Project, although African countries are moving towards greening, the green development has still not become a major issue [11]. 
What causes this phenomenon? Is green production unimportant to them? This has triggered us to think further, and motivates us to find the answers.

In order to explain this phenomenon explicitly, we analyze the relationship between green production and social welfare. According to the definition of Krass, social welfare includes three parts: consumer surplus, environmental benefits, and producer surplus [12], which can provide an effective basis for the government to make macro decisions.

Meanwhile, considering the different distribution of high- and low-income groups in countries, their attitudes and preferences towards green production are different. Especially in low-income people, these people pay more attention to the function and price of products, rather than "green" or "non-green". However, green products are usually expensive, and consuming green products will increase their living expenses and, thus, lower their consuming interests. Therefore, in order to model enterprises' decisions, we use a Hotelling model to analyze the impact of green production decisions on social welfare when green consumers and brown consumers coexist in the market. In contrast to using other models, the Hotelling model has two advantages. First, the horizontal differentiation of green product and non-green product can be analyzed in a more precise way. Meanwhile, second, this model can accurately describe the different consumers' preference and quantity in the market.

In this study, three research questions are properly solved: first, can the enterprise green production improve total social welfare? Second, from the perspective of total social welfare, which public decision is better? All enterprises in the market implement green production, or do only part of the enterprises do so? Finally, what are the effects of the proportion of green consumers and the degree of green preference on social welfare?

We extend the findings of the existing literature. First, we divide the green production scenario into two scenarios. The total social welfare will benefit from green production, while the total social welfare generated by both enterprises conducting green production is not necessarily higher than that generated by only one enterprise conducting green production. Second, the proportion of green consumers has a positive effect on the total social welfare in scenario BG, while the increase in the scale of green consumers has the potential to reduce total social welfare in scenario SG. The in-depth consideration of this topic helps us recognize the relationship between green production and social welfare, and leads to the formulation of green production practices and government-related policies. The paper is organized as below. Section 2 reviews the related work in the literature. Section 3 describes the question and introduces the assumptions. Section 4 presents the model and derives the equilibrium results. Section 5 compares and analyzes the results in three scenarios. Section 6 conducts numerical experiments under different conditions. Section 7 concludes this study. In addition, all proofs are presented in Appendix A.

\section{Literature Review}

In 1996, the American Society of Manufacturing Engineers (SME) published the Blue Book called "Green Manufacturing", which completely proposed the concept of green production, believing that Green manufacturing (GM) had been recognized worldwide as a key strategy for sustainable development and advanced model for manufacturing enterprises [13]. On this basis, the concept of green production has been constantly developed. For example, Shi (2008) defined green production as requiring enterprises to adopt clean production methods and new technologies, and to reduce the use of raw materials and resources to achieve low input, high output, and low pollution [14]. This showed that enterprises not only aimed at maximizing efficiency or minimizing costs in production activities, but also strived for energy saving, consumption reduction, and pollution reduction. Through scientific management and advanced technology, the enterprise's goals could be achieved, thereby saving raw materials and reducing the generation of pollutants, coordinating and optimizing the enterprise economic profit and social benefit. Furthermore, Zhou et al. (2012) proposed that the concepts of environmental protection and energy conservation should be integrated into production and service activities when people implemented green production, while accomplishing the production economy, 
reducing industrial waste, saving energy and scarce resources, and decreasing pollution to the natural environment [15]. Hence, the development of green production theory has laid a theoretical foundation for green production research.

In terms of green production research, many scholars have conducted in-depth research in different aspects. Chen (2001) considered the case of a monopolistic manufacturer of both ordinary and green products, and found that production and stricter environmental standards of green product might not be conducive to the environment [16]. Hu (2014) analyzed the competitive relationship between green manufacturing and general manufacturing, and believed that cost-effectiveness and innovative design were key factors in the production of green products, while demonstrating the effectiveness of tax and subsidy policies in promoting green production [17]. Albino et al. (2012) claimed that the external environment of green product development was very important, which implied that enterprises should develop environmental strategies to support green product design and process development [18]. Liu et al. (2012) focused on product differences and competition among different companies. It was found that enterprises with higher environmental protection operating standards would benefit from enhancement of consumer environmental awareness, while those who were hardly involved in environmental protection activities would only profit when the competitiveness of rival enterprises was low [19]. Zhang et al. (2015) studied the influence of the consumers' environmental awareness and two alternative products (environmental products and traditional products) on green supply chain balance and profit. He found that consumers and companies were increasingly striving to achieve "environmental protection", and the market of environmentally friendly products was expanding. The difference of environmental quality between traditional and green products determined whether the number of orders for traditional products increased or remained the same [20]. The existing works have fully studied the necessity of green production, the importance of government intervention, and the method of making green production decisions when green products and non-green products coexisted, and many significant results have been obtained.

While paying attention to environmental protection and enterprise green production, some scholars have also discussed social welfare issues under green production. Research by Wang et al. (2015) showed that green production could improve environmental and social sustainability, and then increase environmental benefits and social welfare [21]. Conrad (2005) took into account the influence of consumer environmental awareness and green product production costs in the process of green production decision-making, and made decisions based on maximizing social welfare [22]. Taking the three dimensions of sustainability (economy, environment, and social welfare) into account, Sinayi et al. (2018) found that cooperation among members of the supply chain would produce products with higher greenness, which would benefit the whole supply chain and improve consumer welfare [23]. Taking a supply chain system composed of supplier, manufacturer, and the government as the research object, Guo et al. (2016) investigated the effects of government green production subsidies on social welfare and the profit of supply chain members, and then obtained the optimal subsidy policy to maximize social welfare [24]. Sheu et al. (2012) found that green taxes and subsidies adopted by the government could ensure the green profits generated by green production, and the social benefits obtained under this condition were higher than those without government financial intervention [25]. $\mathrm{Hu}$ (2012) studied the competitive relationship between green production and ordinary production in sustainable manufacturing, and discussed the change of social welfare under the tax and subsidy policies [26]. Taking consumer environmental awareness into account, Zhou (2018) researched the impact of carbon tax policy implementation on pricing decisions and social welfare of supply chain members, and Zhou finally found that the government carbon tax regulations at the optimal tax rate could effectively improve social welfare [27].

These studies examined social welfare issues in terms of enterprise, supply chain, and government environmental regulation. Although the above studies considered the differences between green production and non-green production, they ignored classification of the consumers and considered 
that all consumers had green preference and environmental protection awareness. In other words, they ignored the existence of many brown consumers, which means that the actual market situation cannot be reflected in the right way. The research of Guo et al. [28] and Rodriguez-Ibeas [29] involves the classification of consumers, however, their main research was not about green production and social welfare. Given this gap in research, based on the existing research, this paper comprehensively considers the actual situation of consumers in the market and divides consumers into green consumers and brown consumers. In addition, the Hotelling model is used for modeling and analysis. It provides references for enterprises making green production decisions, and provides some insights for the government to formulate regulations and policies.

\section{Problem Description and Assumptions}

There are two enterprises in the market. They produce products with similar basic functions and only have horizontal product differences. In order to improve the environment, enterprise 1 or enterprise 2 can implement green production. The products produced by green production are consistent with non-green products in terms of basic functions, but can increase the environmental attributes.

It is assumed that consumers are uniformly distributed on the interval $[0,1]$ with density one in the linear market. The total size of consumers is $N$, and each consumer has a unit demand. The two competitive enterprises are each located at the two endpoints of the market. We suppose that enterprise 1 is located at the left endpoint and enterprise 2 is located at the right endpoint. The sales price of enterprise $i(i=1,2)$ is $p_{i}$. When green production is not carried out, the greenness of the product is 0 , and the unit production cost is $c$; while, after green production, the greenness of the product is increased to $g_{i}$, which is a decision variable for enterprises that implement green production, and the unit production cost increased $\gamma g_{i}^{2}$ accordingly, where $\gamma(\gamma>0)$ denotes the unit cost coefficient of greenness. For simplicity, we use green products to denote the products that are produced by green production in the following.

We assume that the size of green consumers is $\alpha N$, and the size of brown consumers is $(1-\alpha) N$ in the market, and $\alpha$ is the proportion of green consumers. Green consumers have green preference, focusing on the environmental and physical attributes of products, while brown consumers only value the physical attributes [29]. Based upon the traditional Iyer utility function [30], the utility of brown consumers when they buy green products and non-green products from enterprise $i(i=1,2)$ is given by $U_{n 1}=a-p_{1}-t x$ or $U_{n 2}=a-p_{2}-t(1-x)$; for consumers with green preference, the utility obtained from buying non-green products is consistent with that of brown consumers. However, when they buy green products, they will obtain the utility of environmental preference $\theta g_{i}(i=1,2)$ on the basis of the basic utility, i.e., the utility of purchasing green products from enterprise $i(i=1,2)$ is $U_{g 1}=a+\theta g_{1}-p_{1}-t x$ or $U_{g 2}=a+\theta g_{2}-p_{2}-t(1-x)$, where $a$ is the basic utility gained by buying products for consumers. $a$ is supposed to be sufficiently large, which can guarantee the market is fully covered. In other words, all consumers in the market can obtain positive utility surplus when buying products, and $t x$ is the distance cost that consumers pay for buying products, where $t$ is a distance cost parameter, and $x$ is the distance of the consumer from enterprises. This implies that the per-unit distance costs of a consumer are related to his willingness to pay for product, thereby indicating the loss of utility that consumers afford when they cannot buy the desired product.

According to the basic utility function of consumers, the demand of enterprise 1 and enterprise 2 is given by

$$
\begin{aligned}
& q_{1}=\alpha N \int_{0}^{\bar{x}_{g}} d x+(1-\alpha) N \int_{0}^{\bar{x}_{n}} d x \\
& q_{2}=\alpha N \int_{\bar{x}_{g}}^{1} d x+(1-\alpha) N \int_{\bar{x}_{n}}^{1} d x
\end{aligned}
$$

where $\bar{x}_{g}$ is the threshold for green consumers to purchase products of enterprise 1 and enterprise 2; and $\bar{x}_{n}$ is the threshold for brown consumers to purchase products of enterprise 1 and enterprise 2 . 
The total social welfare consists of three parts—consumer surplus, environmental benefits, and producer surplus [12]—namely

$$
S W=\sum_{i=1}^{2} \pi_{i}+C S+E V
$$

where the consumer surplus can be calculated according to the utility function of consumers, which is

$$
C S=\alpha N \int_{0}^{\bar{x}_{g}} U_{g 1} d x+(1-\alpha) N \int_{0}^{\bar{x}_{n}} U_{n 1} d x+\alpha N \int_{\bar{x}_{g}}^{1} U_{g 2} d x+(1-\alpha) N \int_{\bar{x}_{n}}^{1} U_{n 2} d x
$$

where $\alpha N \int_{0}^{\bar{x}_{g}} U_{g 1} d x$ is the consumer surplus obtained by green consumers to purchase products of enterprise $1 ;(1-\alpha) N \int_{0}^{\bar{x}_{n}} U_{n 1} d x$ is the consumer surplus obtained by brown consumers to purchase products of enterprise $1 ; \alpha N \int_{\bar{x}_{g}}^{1} U_{g 2} d x$ is the consumer surplus obtained by green consumers to purchase products of enterprise 2; and $(1-\alpha) N \int_{\bar{x}_{n}}^{1} U_{n 2} d x$ is the consumer surplus obtained by brown consumers to purchase products of enterprise 2 .

The environmental benefits are based on the study by Hong et al. [31], who assume that the environmental benefits are zero when enterprises do not carry out green production, and the environmental benefits brought by the green production of enterprises are

$$
E V=\sum_{i=1}^{2} k g_{i} q_{i}
$$

where $k$ is unit environmental benefit parameter, which indicates the environmental benefits brought by the improvement of unit greenness and, the higher the $k$, the higher environmental benefits brought by the improvement of greenness.

While producer surplus is represented by the enterprise profit, and when enterprise $i$ conducts green production, the profit function is

$$
\pi_{i}=\left(p_{i}-c-\gamma g_{i}^{2}\right) q_{i}
$$

The profit function when no green production performed is

$$
\pi_{i}=\left(p_{i}-c\right) q_{i}
$$

Assuming that the information of two enterprises is completely symmetrical, they make decisions simultaneously according to the maximization of their own interests, and the game process is divided into two stages. The first stage: the research and development stage, the enterprises determine the green innovation level of the product; the second stage: the production and marketing stage, simultaneously carrying out product pricing, as shown in Figure 1.

enterprise 1 or enterprise 2 decides product greenness enterprise 1 and enterprise 2

decide price

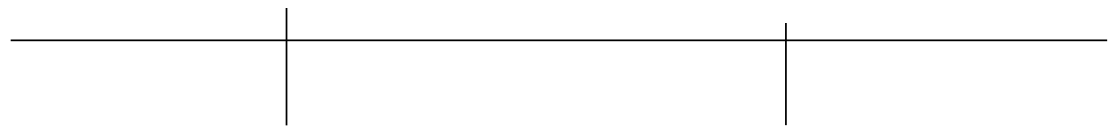

Figure 1. Game sequence. 


\section{Game Model and Solution}

In this section, the green production decisions and achievable social welfare under the following three different scenarios will be analyzed:

- No enterprise implements green production, denoted by superscript "NG": the two enterprises only carry out price game.

- Only one enterprise implements green production, denoted by superscript "SG": as an enterprise that conducts green production, enterprise 1 first makes the product greenness decision, and then enterprise 1 and enterprise 2 make the price decisions simultaneously.

- Both enterprises implement green production denoted by superscript "BG": enterprise 1 and enterprise 2 simultaneously make decisions on product greenness firstly, and then they make price decisions.

Then, we use superscripts including "NG", "SG", and "BG" to indicate the three scenarios of green production of enterprises (no enterprises implement green production, only one enterprise implements green production, and both enterprises implement green production) and the subscript, including " 1 " and "2", to index the enterprise members throughout this paper.

\subsection{Benchmark: No Enterprise Implements Green Production (Marked as Scenario NG)}

Firstly, we consider a benchmark that no enterprise implements green production. In this scenario, the utility of green consumers and brown consumers in purchasing products of enterprise 1 and enterprise 2, respectively, is

$$
\begin{cases}U_{g 1}=U_{n 1}=a-p_{1}-t x & \text { purchase product 1 } \\ U_{g 2}=U_{n 2}=a-p_{2}-t(1-x) & \text { purchase product 2 }\end{cases}
$$

When $a-p_{1}-t x=a-p_{2}-t(1-x), \bar{x}_{g}=\bar{x}_{n}=\frac{p_{2}-p_{1}+t}{2 t}$ can be obtained, which means that there is no difference between green consumers and brown consumers buying products of enterprise 1 and enterprise 2 at $\frac{p_{2}-p_{1}+t}{2 t}$. That is, consumers in interval $\left[0, \frac{p_{2}-p_{1}+t}{2 t}\right]$ will buy products of enterprise 1 , while consumers in interval $\left[\frac{p_{2}-p_{1}+t}{2 t}, 1\right]$ will choose products of enterprise 2 . The demand functions of enterprise 1 and enterprise 2 are given by

$$
\begin{gathered}
q_{1}=N \int_{0}^{\frac{p_{2}-p_{1}+t}{2 t}} d x=N \frac{p_{2}+t-p_{1}}{2 t} \\
q_{2}=N \int_{\frac{p_{2}-p_{1}+t}{2 t}}^{1} d x=N\left(1-\frac{p_{2}+t-p_{1}}{2 t}\right)
\end{gathered}
$$

The profit functions of the enterprise 1 and the enterprise 2 are

$$
\begin{aligned}
& \pi_{1}=\left(p_{1}-c\right) q_{1} \\
& \pi_{2}=\left(p_{2}-c\right) q_{2}
\end{aligned}
$$

In the case of scenario NG, the two enterprises only carry out the price game. The game model is

$$
\begin{aligned}
& \max _{p_{1}}\left(N\left(p_{1}-c\right) \frac{p_{2}+t-p_{1}}{2 t}\right) \\
& \max _{p_{2}}\left(N\left(p_{2}-c\right)\left(1-\frac{p_{2}+t-p_{1}}{2 t}\right)\right)
\end{aligned}
$$

According to this game model, equilibrium retail price and equilibrium product sales volume can be obtained as follows

$$
p_{1}^{N G *}=p_{2}^{N G *}=t+c ; q_{1}^{N G *}=q_{2}^{N G *}=\frac{N}{2} .
$$


Consequently, we derive enterprise profit, total consumer surplus, environmental benefits, and social welfare based upon the above equilibrium solutions:

$$
\begin{gathered}
\pi_{1}^{N G *}=\pi_{2}^{N G *}=\frac{N t}{2} ; C S^{N G *}=N\left(a-\frac{5 t}{4}-c\right) ; E V^{N G *}=0 ; \\
S W^{N G *}=N\left(a-\frac{t}{4}-c\right) .
\end{gathered}
$$

\subsection{Only One Enterprise Implements Green Production (Marked as Scenario SG)}

We assume enterprise 1 implements green production, while enterprise 2 maintains the non-green mode of production. In this scenario, the utility of green consumers in purchasing products of enterprise 1 and enterprise 2, respectively, is

$$
\begin{cases}U_{g 1}=a+\theta g_{1}-p_{1}-t x & \text { purchase product } 1 \\ U_{g 2}=a-p_{2}-t(1-x) & \text { purchase product } 2\end{cases}
$$

The utility of brown consumers in purchasing products of enterprise 1 and enterprise 2, respectively, is

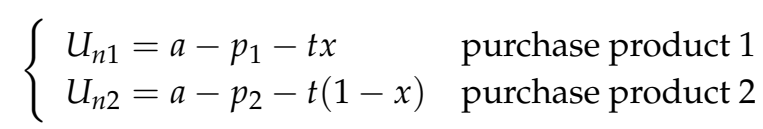

When $U_{g 1}=U_{g 2}$, it can be seen that there is no difference for green consumers to buy products of enterprise 1 and enterprise 2 at $\bar{x}_{g}=\frac{p_{2}+\theta g+t-p_{1}}{2 t}$. When $U_{n 1}=U_{n 2}$, there is no difference for brown consumers to buy products of enterprise 1 and enterprise 2 at $\bar{x}_{n}=\frac{p_{2}+t-p_{1}}{2 t}$.

The demand function of enterprise 1 and the demand function of enterprise 2 are given by

$$
\begin{gathered}
q_{1}=\alpha N \int_{0}^{\bar{x}_{g}} d x+(1-\alpha) N \int_{0}^{\bar{x}_{n}} d x=N \frac{p_{2}+t+\alpha \theta g_{1}-p_{1}}{2 t} \\
q_{2}=\alpha N \int_{\bar{x}_{g}}^{1} d x+(1-\alpha) N \int_{\bar{x}_{n}}^{1} d x=N\left(1-\frac{p_{2}+t+\alpha \theta g_{1}-p_{1}}{2 t}\right)
\end{gathered}
$$

The profit functions of the two enterprises are given by

$$
\begin{gathered}
\pi_{1}=\left(p_{1}-c-\gamma g_{1}^{2}\right) q_{1} \\
\pi_{2}=\left(p_{2}-c\right) q_{2}
\end{gathered}
$$

As for the scenario SG, the game process is divided into two stages, enterprise 1 first makes the product greenness decision. The decision objective of enterprise 1 is

$$
\max _{g_{1}}\left(N\left(p_{1}-c-\gamma g_{1}^{2}\right) \frac{p_{2}+t+\alpha \theta g_{1}-p_{1}}{2 t}\right)
$$

and then enterprise 1 and enterprise 2 make the price decisions simultaneously. The decision objective of enterprise 1 and enterprise 2, respectively, is

$$
\begin{gathered}
\max _{p_{1}}\left(N\left(p_{1}-c-\gamma g_{1}^{2}\right) \frac{p_{2}+t+\alpha \theta g_{1}-p_{1}}{2 t}\right) \\
\max _{p_{2}}\left(N\left(p_{2}-c\right)\left(1-\frac{p_{2}+t+\alpha \theta g_{1}-p_{1}}{2 t}\right)\right)
\end{gathered}
$$

According to the game process, the backward induction method is used to solve the problem. Then, the equilibrium product greenness, equilibrium retail price, and equilibrium product sales volume can be obtained as follows:

$$
g_{1}^{S G^{*}}=\frac{\alpha \theta}{2 \gamma} ; p_{1}^{S G *}=t+c+\frac{4 \alpha^{2} \theta^{2}}{12 \gamma}, p_{2}^{S G *}=t+c-\frac{\alpha^{2} \theta^{2}}{12 \gamma} ; q_{1}^{S G *}=\frac{N}{2 t}\left(t+\frac{\alpha^{2} \theta^{2}}{12 \gamma}\right),
$$


$q_{2}^{S G *}=\frac{N}{2 t}\left(t-\frac{\alpha^{2} \theta^{2}}{12 \gamma}\right)$, among them, $t>\frac{\alpha^{2} \theta^{2}}{12 \gamma}$. Without loss of generality, the sales volume of enterprise 2 is greater than or equal to 0 , so $t>\frac{\alpha^{2} \theta^{2}}{12 \gamma}$.

Consequently, we derive enterprise profit, total consumer surplus, environmental benefits, and social welfare based upon the above equilibrium solutions:

$$
\begin{gathered}
\pi_{1}^{S G *}=\frac{N}{2 t}\left(t+\frac{\alpha^{2} \theta^{2}}{12 \gamma}\right)^{2}, \pi_{2}^{S G *}=\frac{N}{2 t}\left(t-\frac{\alpha^{2} \theta^{2}}{12 \gamma}\right)^{2} ; \\
C S^{S G *}=N\left(a-\frac{5 t}{4}-c\right)+\frac{N \alpha^{2} \theta^{2}}{8 \gamma}+\frac{N \alpha^{3} \theta^{4}}{16 t \gamma^{2}}\left(1-\frac{35 \alpha}{36}\right) ; E V^{S G *}=\frac{N k \alpha \theta}{4 \gamma t}\left(t+\frac{\alpha^{2} \theta^{2}}{12 \gamma}\right) ; \\
S W^{S G *}=N\left(a-\frac{t}{4}-c\right)+\frac{N \alpha^{2} \theta^{2}}{8 \gamma}+\frac{N \alpha^{3} \theta^{4}}{16 t \gamma^{2}}\left(1-\frac{11 \alpha}{12}\right)+\frac{N k \alpha \theta}{4 \gamma t}\left(t+\frac{\alpha^{2} \theta^{2}}{12 \gamma}\right) .
\end{gathered}
$$

\subsection{Both Enterprises Implement Green Production (Marked as Scenario BG)}

As for the scenario BG, the utility of green consumers in purchasing products of enterprise 1 and enterprise 2, respectively, is:

$$
\begin{cases}U_{g 1}=a+\theta g_{1}-p_{1}-t x & \text { purchase product 1 } \\ U_{g 2}=a+\theta g_{2}-p_{2}-t(1-x) & \text { purchase product 2 }\end{cases}
$$

The utility of brown consumers in purchasing products of enterprise 1 and enterprise 2, respectively, is

$$
\begin{cases}U_{n 1}=a-p_{1}-t x & \text { purchase product } 1 \\ U_{n 2}=a-p_{2}-t(1-x) & \text { purchase product } 2\end{cases}
$$

When $U_{g 1}=U_{g 2}$, it can be seen that there is no difference for green consumers to buy products of enterprise 1 and enterprise 2 at $\bar{x}_{g}=\frac{p_{2}+\theta\left(g_{1}-g_{2}\right)+t-p_{1}}{2 t}$. When $U_{n 1}=U_{n 2}$, there is no difference for brown consumers to buy products of enterprise 1 and enterprise 2 at $\bar{x}_{n}=\frac{p_{2}+t-p_{1}}{2 t}$.

Therefore, the demand functions of enterprise 1 and enterprise 2 are given by

$$
\begin{gathered}
q_{1}=N \frac{p_{2}-p_{1}+\alpha \theta\left(g_{1}-g_{2}\right)+t}{2 t} \\
q_{2}=N\left[1-\frac{p_{2}-p_{1}+\alpha \theta\left(g_{1}-g_{2}\right)+t}{2 t}\right]
\end{gathered}
$$

The profit functions of the two enterprises are represented by

$$
\begin{aligned}
& \pi_{1}=\left(p_{1}-c-\gamma g_{1}{ }^{2}\right) q_{1} \\
& \pi_{2}=\left(p_{2}-c-\gamma g_{2}^{2}\right) q_{2}
\end{aligned}
$$

In this two-stage game of scenario BG, enterprise 1 and enterprise 2 simultaneously make decisions on product greenness firstly. The decision objective of enterprise 1 and enterprise 2, respectively, is:

$$
\begin{aligned}
& \max _{g_{1}}\left(N\left(p_{1}-c-\gamma g_{1}^{2}\right) \frac{p_{2}+\theta\left(g_{1}-g_{2}\right)+t-p_{1}}{2 t}\right) \\
& \max _{g_{2}}\left(N\left(p_{2}-c-\gamma g_{2}^{2}\right)\left(1-\frac{p_{2}+\theta\left(g_{1}-g_{2}\right)+t-p_{1}}{2 t}\right)\right)
\end{aligned}
$$

and then they make price decisions simultaneously. The decision objective of enterprise 1 and enterprise 2, respectively, is

$$
\begin{aligned}
& \max _{p_{1}}\left(N\left(p_{1}-c-\gamma g_{1}^{2}\right) \frac{p_{2}+\theta\left(g_{1}-g_{2}\right)+t-p_{1}}{2 t}\right) \\
& \max _{p_{2}}\left(N\left(p_{2}-c-\gamma g_{2}^{2}\right)\left(1-\frac{p_{2}+\theta\left(g_{1}-g_{2}\right)+t-p_{1}}{2 t}\right)\right)
\end{aligned}
$$


According to the game process, the backward induction method is used to solve the problem. Then, equilibrium product greenness, equilibrium retail price, and equilibrium product sales volume can be obtained as follows:

$$
g_{1}^{B G *}=g_{1}^{B G *}=\frac{\alpha \theta}{2 \gamma} ; p_{1}^{B G *}=p_{2}^{B G *}=t+c+\frac{3 \gamma \alpha^{2} \theta^{2}}{12} ; q_{1}^{B G *}=q_{2}^{B G *}=\frac{N}{2} .
$$

Consequently, we derive enterprise profit, total consumer surplus, environmental benefits, and social welfare based upon the above equilibrium solutions:

$$
\begin{gathered}
\pi_{1}^{B G *}=\pi_{2}^{B G *}=\frac{N t}{2} ; C S^{B G *}=N\left(a-\frac{5 t}{4}-c\right)+\frac{N \alpha^{2} \theta^{2}}{4 \gamma} ; E V^{B G *}=\frac{N k \alpha \theta}{2 \gamma} ; \\
S W^{B G *}=N\left(a-\frac{t}{4}-c\right)+\frac{N \alpha^{2} \theta^{2}}{4 \gamma}+\frac{N k \alpha \theta}{2 \gamma} .
\end{gathered}
$$

\section{Model Analysis}

In this section, we first compare and analyze the equilibrium solutions in three scenarios, especially in focusing on the differences between enterprise profit, environmental benefits, consumer surplus, and social welfare, and then discuss how the proportion of green consumers, the degree of consumer green preference, and unit of environmental benefit parameters affect social welfare.

For comparing and analyzing the equilibrium of the enterprise profit, environmental benefits, consumer surplus, and social welfare, we summarize the outcomes in Table 1.

Table 1. Equilibrium values in different scenarios.

\begin{tabular}{cccc}
\hline & NG & SG & BG \\
\hline $\begin{array}{c}\text { Enterprise 1 } \\
\text { and 2 profit }\end{array}$ & $N t$ & $\frac{N}{2 t}\left(t+\frac{\alpha^{2} \theta^{2}}{12 \gamma}\right)^{2}+\frac{N}{2 t}\left(t-\frac{\alpha^{2} \theta^{2}}{12 \gamma}\right)^{2}$ & $N t$ \\
\hline $\begin{array}{c}\text { Environmental } \\
\text { benefits }\end{array}$ & 0 & $\frac{N k \alpha \theta}{4 \gamma t}\left(t+\frac{\alpha^{2} \theta^{2}}{12 \gamma}\right)$ & $\frac{N k \alpha \theta}{2 \gamma}$ \\
\hline $\begin{array}{c}\text { Consumer } \\
\text { surplus }\end{array}$ & $N\left(a-\frac{5 t}{4}-\mathrm{c}\right)$ & $N\left(a-\frac{5 t}{4}-\mathrm{c}\right)+\frac{N \alpha^{2} \theta^{2}}{8 \gamma}+\frac{N \alpha^{3} \theta^{4}}{16 t \gamma^{2}}\left(1-\frac{35 \alpha}{36}\right)$ & $N\left(a-\frac{5 t}{4}-\mathrm{c}\right)+\frac{N \alpha^{2} \theta^{2}}{4 \gamma}$ \\
\hline Social welfare & $N\left(a-\frac{t}{4}-\mathrm{c}\right)$ & $N\left(a-\frac{t}{4}-\mathrm{c}\right)+\frac{N \alpha^{2} \theta^{2}}{8 \gamma}+\frac{N \alpha^{3} \theta^{4}}{16 t \gamma^{2}}\left(1-\frac{11 \alpha}{12}\right)+\frac{N k \alpha \theta}{4 \gamma t}\left(t+\frac{\alpha^{2} \theta^{2}}{12 \gamma}\right)$ & $N\left(a-\frac{t}{4}-\mathrm{c}\right)+\frac{N \alpha^{2} \theta^{2}}{4 \gamma}+\frac{N k \alpha \theta}{2 \gamma}$ \\
\hline
\end{tabular}

Proposition 1. The social welfare under the three scenarios satisfies the following relationships: under certain conditions, $S W^{S G *}>S W^{B G *}>S W^{N G *}$; and, in other cases, $S W^{B G *}>S W^{S G *}>S W^{N G *}$ (see Appendix A).

Proposition 1 indicates that when green consumers and brown consumers coexist in the market, only one enterprise implements green production (i.e., scenario SG), or both enterprises implement green production (i.e., scenario BG), and the total social welfare will be higher than that of no enterprise implementing green production (i.e., scenario NG); only when this certain condition is met, then the highest social welfare will be reached in scenario BG. This is because the proportion of green consumers is high at this point, and the demand of green consumers will be met when both enterprises implement green production while, under other conditions, the highest total social welfare will be reached in scenario SG. The main reason is that when there are a large number of brown consumers in the market, green production conducted by both enterprises cannot meet the needs of the majority of brown consumers. Therefore, it is not conducive to the improvement of the overall interests of consumers, and thus decreases the social welfare. This conclusion illustrates that it is not always the right case that both enterprises implement production, which is beneficial to the total social welfare. Therefore, from the perspective of total social welfare, it can also explain the phenomenon that different governments have diverse attitudes towards green development to some extent, namely, why in many developing countries, some governments acquiesce to the non-green production mode of some enterprises. 
Proposition 2. $\pi_{1}^{S G *}+\pi_{2}^{S G *}>\pi_{1}^{N G *}+\pi_{2}^{N G *} ; \pi_{1}^{S G *}+\pi_{2}^{S G *}>\pi_{1}^{B G *}+\pi_{2}^{B G *}$.

Proposition 2 demonstrates that when green consumers and brown consumers coexist in the market, from the perspective of total producer surplus, only one enterprise implements green production (i.e., scenario SG), the total producer surplus of the enterprises will reach the highest peak. The main reason is that, when green products and non-green products coexist in the market, they can meet the demands of green consumers and brown consumers simultaneously. However, if both enterprises in the market implement green production (i.e., scenario BG), this will actually hurt the interests of brown consumers. This also explains why some governments ignore the environmental problems of some traditional manufacturing enterprises and never implement the strict policies of environmental protection for the sake of economic efficiency.

Proposition 3. The environmental benefits under the three scenarios satisfy the following relationships: $E V^{B G *}>E V^{S G *}>E V^{N G *}$.

Proposition 3 shows that as long as one of enterprises implements green production, it will be beneficial to the environment, and if both enterprises in the market carry out green production (i.e., scenario BG), the highest environmental benefits will be reached. This is due to the fact that the implementation of green production can reduce emissions that are harmful to the ecosystem and, thus, increase environmental benefits. Therefore, from the perspective of improving the ecological environment, the government should encourage more enterprises to carry out green production and innovation.

Proposition 4. Under certain conditions, $C S^{S G *}>C S^{B G *}>C S^{N G *}$; and, in other cases, $C S^{B G *}>C S^{S G *}>$ $\mathrm{CS}^{N G *}$ (see Appendix A).

Proposition 4 claims that when green consumers and brown consumers coexist in the market, and only one enterprise implements green production (i.e., scenario SG) or both enterprises implement green production (i.e., scenario BG), the consumer surplus will be higher than that of no enterprise implementing green production (i.e., scenario NG); only when this certain condition is met, then the highest consumer surplus will be reached in scenario BG; under other conditions, in scenario SG, the highest consumer surplus will be reached. The main reason is that when there are more brown consumers in the market, if both enterprises implement green production, it will damage the interests of brown consumers instead, and is not conducive to the improvement of the overall interests of consumers. However, when there are a large number of green consumers in the market, only one enterprise carrying out green production (i.e., scenario SG) will lead to the unmet demand of consumers, and some green consumers cannot buy green products, which also impedes the improvement of consumers' overall welfare. This conclusion further demonstrates that it is not always the right case that both enterprises in the market implement production (i.e., scenario BG), which is beneficial to consumer. Therefore, from the perspective of consumer surplus, it can also explain why some governments acquiesce to the non-green production mode of some enterprises in some developing countries.

Proposition 5. $\frac{\partial S W^{B G *}}{\partial \alpha}>0$; under the certain condition, there is $\frac{\partial S W^{S G *}}{\partial \alpha}>0$; and, in other cases, there is $\frac{\partial S W^{S G *}}{\partial \alpha}<0$ (see Appendix A).

Proposition 5 states that in scenario SG, if the certain condition is met, the social welfare increases as the proportion of green consumers rises. However, in scenario BG, as the proportion of green consumers increases, the total social welfare will increase. This means that under the certain condition, when only one enterprise engages in green production (i.e., scenario SG), as the proportion of green consumers increases, it cannot meet the needs of the majority of green consumers. Therefore, total social welfare will have a downward trend. However, when both enterprises carry out green production 
(i.e., scenario BG), the demand of all green consumers will be met, and the total social welfare will increase as the size of green consumers expands. As a result, it is necessary for the government to urge enterprises to change their non-green production methods into implementing green production when there are more green consumers, meanwhile, less green production enterprises in the market.

Proposition 6. $\frac{\partial S W^{B G *}}{\partial \theta}>0 ; \frac{\partial S W^{S G *}}{\partial \theta}>0$.

Proposition 6 indicates that, no matter whether only one enterprise implements green production (i.e., scenario SG), or both enterprises carry out green production (i.e., scenario BG), the total social welfare is always positively related to the degree of consumer green preference. The main reason is that the increase of the degree of consumer green preference will lead consumers to prefer green products, reducing environmental pollution and, thus, increasing social welfare. It is shown that the higher the degree of consumer green preference in the market, the higher the necessity for enterprises to implement green production. For governments, in order to improve the total social welfare, they not need to only pay attention to the environment and economic benefits, but it is also necessary to popularize and educate environmental protection knowledge to consumers, enhance their green and environmental awareness, and cultivate their green consumption concept.

Proposition 7. $\frac{\partial S W^{B G *}}{\partial k}>0 ; \frac{\partial S W^{S G *}}{\partial k}>0$.

Proposition 7 reveals that no matter if only one enterprise implements green production (i.e., scenario SG), or both enterprises carry out green production (i.e., scenario BG), the unit of environmental benefit parameters has a positive effect on the total social welfare. It comes from that the increase of the unit of environmental benefit parameter can lead to an increase in environmental benefits and thus increase the social welfare. This means that the higher the environmental benefits are brought by enterprises' green production, the higher the total social welfare that will be created. Moreover, it also explains why many governments are clamping down on highly polluting enterprises and industries, urging them to implement green development.

\section{Numerical Analysis}

For the purpose of further verifying the validity of the conclusions, this paper numerically analyzes the social welfare obtained in different situations.

Firstly, we study the effects of the proportion of green consumers (i.e., $\alpha$ ) on social welfare. Let $\alpha$ range between 0 and 1; our numerical analysis uses the following values to establish ranges for model parameters: $\gamma=1, \theta=1, c=1, t=0.09, N=200, a=2$, and $k=0.1$. Figure 2 can be obtained through MATLAB simulation.

From Figure 2, we can obtain the following facts. (i) When only one enterprise carries out green production (i.e., scenario SG), social welfare will increase as the proportion of green consumers increases at the beginning, but when the proportion of green consumers is high enough, social welfare will decrease as the proportion of green consumers increases. This shows that, in fact, the increase in the scale of green consumers is not necessarily conducive to the improvement of social welfare in scenario SG, because many green consumers cannot buy green products. In other words, green products cannot meet the needs of all green consumers. As a result, social welfare may be reduced. In order to ensure the promotion of social welfare, the government should introduce more stringent environmental policies and urge more enterprises to carry out green production. (ii) In addition, it can be seen that when both enterprises implement green production (i.e., scenario BG), a rise in the proportion of green consumers will increase the social welfare. Therefore, in this scenario, in order to improve the total social welfare, the government can actively guide and promote the concept of green consumption of consumers and encourage them to conduct green consumption. (iii) Meanwhile, it can be obtained that the social welfare in scenarios SG and BG is higher than that in scenario NG and, in scenario SG, the social welfare 
exceeds that in scenario BG, within a certain range. Therefore, for the government, it is necessary to formulate environmental policies according to the actual situation, and take corresponding measures to guide and constrain enterprises to push green production into practice.

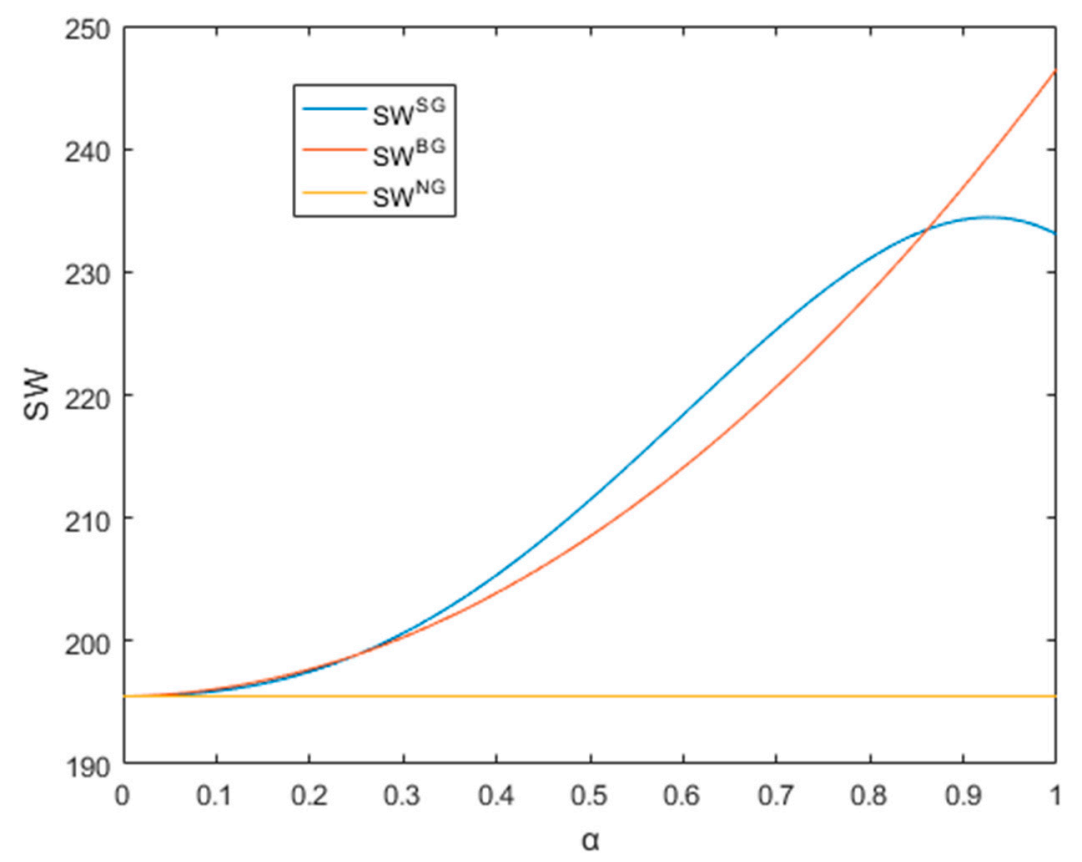

Figure 2. The influence of the proportion of green consumers on the total social welfare in three scenarios.

Secondly, we investigate the effects of the degree of consumer green preference on social welfare under three circumstances. Let $\theta$ range between 0 and 1 , then, we keep the following parameters with values fixed: $\gamma=1, \alpha=0.5, c=1, t=0.05, N=200, a=2$, and $k=0.1$. Figure 3 can be obtained through MATLAB simulation.

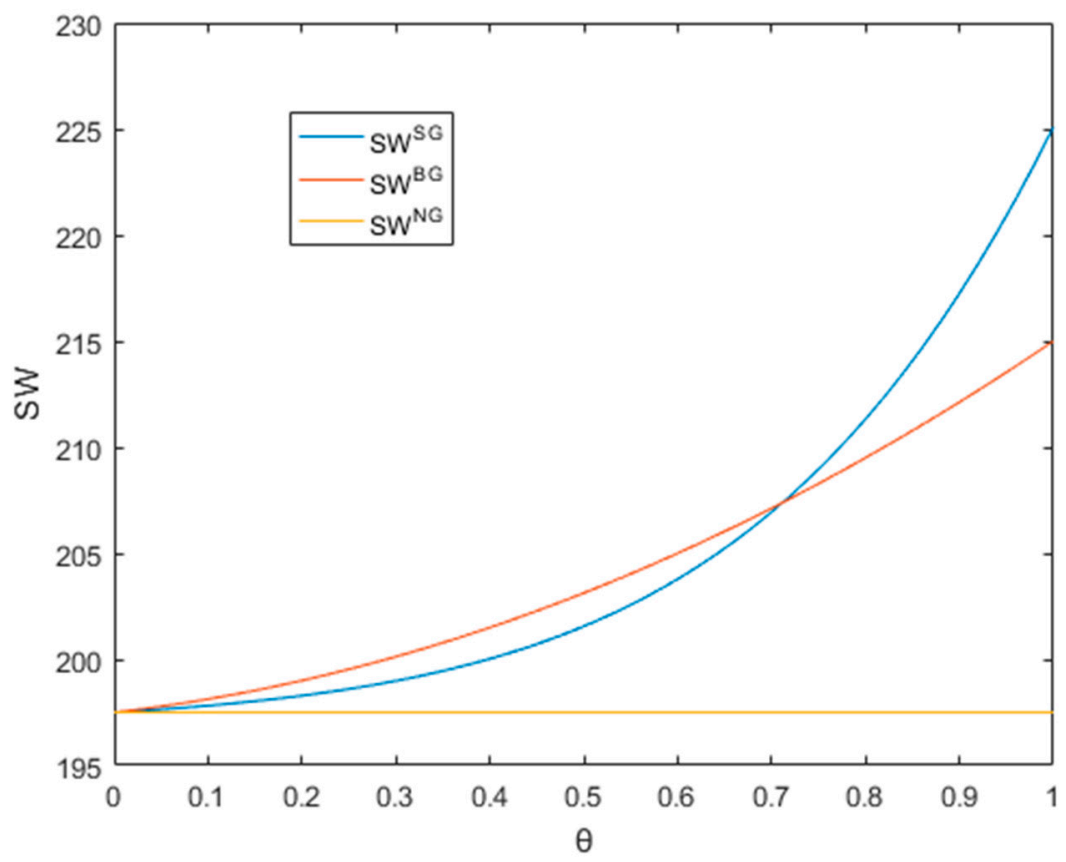

Figure 3. The influence of the degree of green preference on the total social welfare in three scenarios. 
Figure 3 offers the following implications. (i) As long as one enterprise conducts green production, the generated social welfare will be higher than that generated by the enterprise without implementing green production (i.e., scenario NG) and, under the certain condition, the social welfare in scenario SG will be higher than that in scenario BG. (ii) At the same time, it also shows that as long as one enterprise conducts green production, the social welfare will increase as the green preference of consumers increases, which implies that more attention to the environmental attributes of products will be more beneficial to improving social welfare. Therefore, it is necessary to strengthen education on environmental protection and cultivate consumer environmental awareness.

Finally, under the different conditions, we research the impact of the unit of environmental benefit parameters on social welfare. Let $k$ range between 0 and 2, then, we keep the following parameters with values fixed: $\gamma=1, \alpha=0.5, \theta=1, c=1, t=0.05, N=200$, and $a=2$. Figure 3 can be obtained through MATLAB simulation.

Figure 4 shows that as long as there is an enterprise to carry out green production, the social welfare level will increase as the unit of environmental parameters increases, which implies that more environmental benefits generated by implementing green production will be good for social welfare promotion. Therefore, for industries with large environmental pollution and significant environmental benefits, the government should vigorously constrain the non-green production mode, and urge and encourage them to carry out green production.

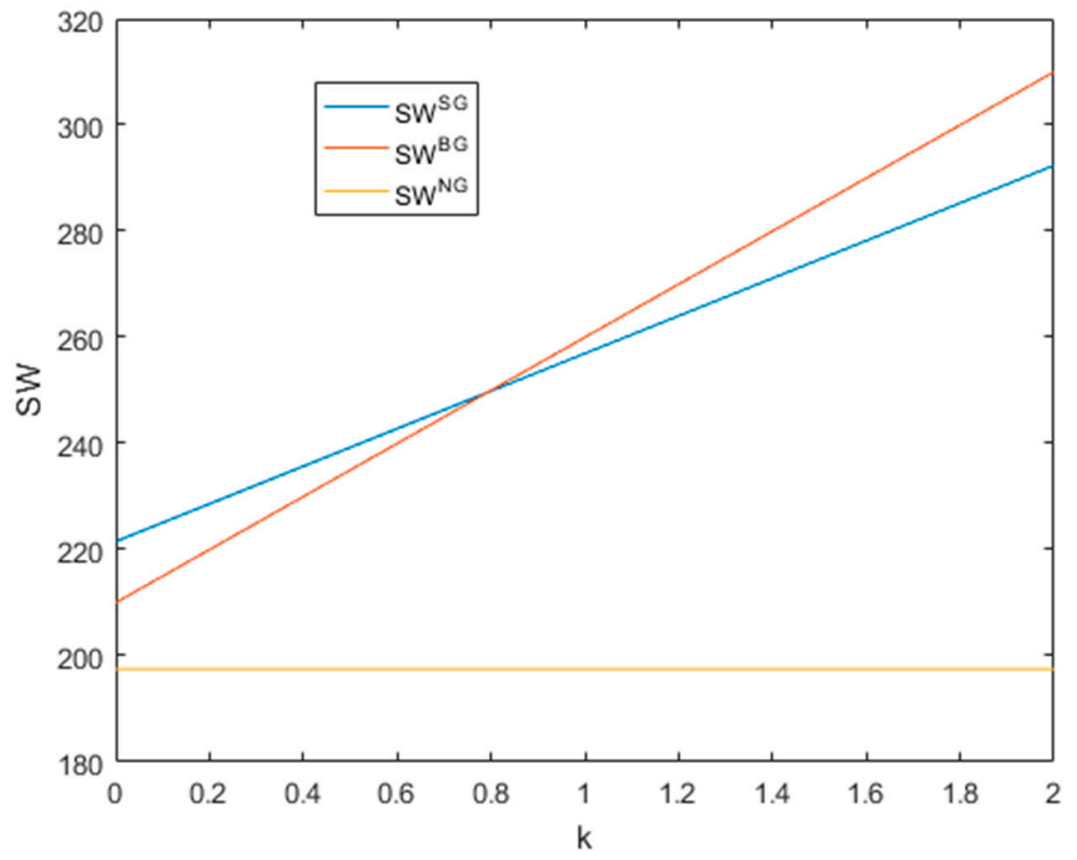

Figure 4. The influence of the unit of environmental benefit parameters on the total social welfare in three scenarios.

\section{Conclusions}

The present study mainly investigates the impact of green production of enterprises on social welfare. During the research process, it is assumed that there are two types of consumers in the market, which can be divided into green consumers and brown consumers. Under this premise, intriguing findings in this paper can accordingly be summarized as:

(i) When green consumers and brown consumers coexist in the market, as long as one enterprise carries out green production, the total social welfare and consumer surplus will be improved. Besides, only under the certain condition will the total social welfare and consumer surplus in scenario BG be higher than that in scenario SG. However, in terms of the total economic 
benefits of the society, only one enterprise implementing green production (i.e., scenario SG) reaches the highest value. From an environmental point of view, when both enterprises carry out green production (i.e., scenario BG), it will have the highest environmental benefits. Based on above conclusions, it can be obtained that green production conducted by both enterprises (i.e., scenario BG) does not necessarily benefit the total social welfare. If there are a large number of brown consumers in the market, both enterprises blindly carry out green production, which will harm the interests of brown consumers. To some degree, this conclusion explains the phenomenon that different governments have diverse attitudes towards green development. Therefore, the government should encourage enterprises to conduct green production, but they cannot simply adopt green development as the only goal. It is better for the government to comprehensively consider the actual situation of the society (environment, economic and the needs of brown consumers, etc.) and formulate reasonable measures from the perspective of the total social welfare.

(ii) When both enterprises carry out green production (i.e., scenario BG), social welfare will increase with the increasing proportion of green consumers. However, if only one enterprise implements green production (i.e., scenario SG), under the certain condition, the social welfare increases more, as the proportion of green consumers becomes high, otherwise, it will decrease with the increasing proportion of green consumers. This indicates that the increase in the scale of green consumers has the potential to reduce total social welfare. This conclusion reflects that when the green production is insufficient in the market, some green consumers' interests will be hurt as the scale of green consumers increases, and thus decrease the total social welfare. However, when the green production is sufficient in the market, the total social welfare will benefit from the higher proportion of green consumers. Therefore, with the increase of green consumers, in order to satisfy their demand for green products, the government should introduce more stringent environmental policies and encourage more enterprises to implement green production.

(iii) The social welfare will increase, as the degree of consumer green preference and the unit of environmental benefit parameters increases in scenario SG and scenario BG. This means that, the higher the green preference of consumers and the higher the environmental benefits brought by green production, the higher the social welfare. Therefore, the government and enterprises should pay more attention to this. On the one hand, for the enterprises, they should actively implement green production, catering to the needs of consumers as well as enhancing their own competitive advantages. On the other hand, for the government, to further improve the total social welfare level, it is necessary to comprehensively consider the interests of consumers and the benefits of ecological environment. In addition, measures should be taken to guide and protect the green production practices of enterprises through formulating relevant policies and laws.

Although this study has made contributions to the green production and social welfare literature, several directions still remain for future research. In this paper, we only consider the situation that there are two enterprises in the market, which can be expanded to multi-members to study a more practical phenomenon considering competition between enterprises. In addition, the market is assumed to be fully covered, which may be slightly different from the reality. Therefore, the situation of partial market coverage can be explored in future research.

Author Contributions: Z.Z. conceived and designed the model; Z.Z. and Y.W. wrote the paper; Q.M. and X.L. critiqued the defects of draft. All authors read and improved the final manuscript.

Funding: This research is funded by the National Nature Science Foundation of China (Grant No. 71572096), Shandong University Foundation of Special Research Topics for the 40th Anniversary of Reform and Opening-up and the 70th Anniversary of the Founding of New China (Grant No. HSS1807).

Acknowledgments: Thanks to all the students in the research group, they give us many valuable suggestions in the process of our writing.

Conflicts of Interest: The authors declare no conflict of interest. 


\section{Appendix A}

Proofs of Proposition 1. $S W^{B G *}-S W^{S G *}=\frac{N \alpha^{2} \theta^{2}}{8 \gamma}\left[1-\frac{\alpha \theta^{2}}{2 t \gamma}\left(1-\frac{11 \alpha}{12}\right)\right]+\frac{N k \alpha \theta}{4 \gamma t}\left(t-\frac{\alpha^{2} \theta^{2}}{12 \gamma}\right)$, when $\frac{N \alpha \theta}{4 \gamma}\left[\frac{\alpha \theta}{2}\left[1-\frac{\alpha \theta^{2}}{2 t \gamma}\left(1-\frac{11 \alpha}{12}\right)\right]+\frac{N k \alpha \theta}{4 \gamma}\left(1-\frac{\alpha^{2} \theta^{2}}{12 t \gamma}\right)>0\right.$ is satisfied, it can be seen that $S W^{B G^{*}}>S W^{S G^{*}}$, that is $\frac{\alpha \theta}{2}\left[1-\frac{\alpha \theta^{2}}{2 t \gamma}\left(1-\frac{11 \alpha}{12}\right)\right]+k\left(1-\frac{\alpha^{2} \theta^{2}}{12 t \gamma}\right)>0$, and thus, $k>\frac{\frac{\alpha \theta}{2}\left[\frac{\alpha \theta^{2}}{2 t \gamma}\left(1-\frac{11 \alpha}{12}\right)-1\right]}{1-\frac{\alpha^{2} \theta^{2}}{12 \gamma t}}$, simplified $k>$ $\frac{3 \alpha \theta\left[\alpha \theta^{2}(1-11 \alpha / 12)-2 t \gamma\right]}{12 \gamma t-\alpha^{2} \theta^{2}}$. Therefore, when $k>\frac{3 \alpha \theta\left[\alpha \theta^{2}(1-33 \alpha / 36)-2 t \gamma\right]}{12 \gamma t-\alpha^{2} \theta^{2}}$, we can obtain $S W^{B G *}>S W^{S G *}>$ $S W^{N G *}$; when $k<\frac{3 \alpha \theta\left[\alpha \theta^{2}(1-33 \alpha / 36)-2 t \gamma\right]}{12 \gamma t-\alpha^{2} \theta^{2}}$, we can obtain $S W^{S G *}>S W^{B G *}>S W^{N G *}$.

The proof is completed.

Proofs of Proposition 4. $C S^{B G *}-C S^{S G *}=\frac{N \alpha^{2} \theta^{2}}{8 \gamma}-\frac{N \alpha^{3} \theta^{4}}{16 t \gamma^{2}}\left(1-\frac{35 \alpha}{36}\right)=\frac{N \alpha^{2} \theta^{2}}{8 \gamma}\left[1-\frac{\alpha \theta^{2}}{2 t \gamma}\left(1-\frac{35 \alpha}{36}\right)\right]$, when $1-\frac{\alpha \theta^{2}}{2 t \gamma}\left(1-\frac{35 \alpha}{36}\right)<0$, and since $t-\frac{\alpha^{2} \theta^{2}}{12 \gamma}>0$, so in the case of $\frac{\alpha^{2} \theta^{2}}{12 \gamma}<t<\frac{\alpha \theta^{2}}{2 \gamma}\left(1-\frac{35 \alpha}{36}\right)$, we can obtain $C S^{B G *}<C S^{S G *}$. And when $t>\frac{\alpha^{2} \theta^{2}}{12 \gamma}$ and $t>\frac{\alpha \theta^{2}}{2 \gamma}\left(1-\frac{35 \alpha}{36}\right)$ are met simultaneously, $1-\frac{\alpha \theta^{2}}{2 t \gamma}\left(1-\frac{35 \alpha}{36}\right)>0$, we can obtain $C S^{B G *}>C S^{S G *}$.

The proof is completed.

Proofs of Proposition 5. $\frac{\partial S W^{B G *}}{\partial \alpha}=\frac{N \alpha \theta^{2}+N k \theta}{2 \gamma}>0$; while $\frac{\partial S W^{S G *}}{\partial \alpha}=\frac{N \alpha \theta^{2}+N k \theta}{4 \gamma}-\frac{11 \alpha^{3} \theta^{4} N}{48 t \gamma^{2}}+$ $\frac{9 \alpha^{2} \theta^{4} N+3 \alpha^{2} \theta^{3} k N}{48 t \gamma^{2}}$, when $\frac{N \alpha \theta^{2}+N k \theta}{4 \gamma}-\frac{11 \alpha^{3} \theta^{4} N}{48 t \gamma^{2}}+\frac{9 \alpha^{2} \theta^{4} N+3 \alpha^{2} \theta^{3} k N}{48 t \gamma^{2}}>0$, that is, if $\alpha \theta+k+\frac{3 \alpha^{2} \theta^{3}+\alpha^{2} \theta^{2} k}{4 t \gamma}>\frac{11 \alpha^{3} \theta^{3}}{12 t \gamma}$ is satisfied, we can obtain $\frac{\partial S W^{S G *}}{\partial \alpha}>0$, while when $\alpha \theta+k+\frac{3 \alpha^{2} \theta^{3}+\alpha^{2} \theta^{2} k}{4 t \gamma}<\frac{11 \alpha^{3} \theta^{3}}{12 t \gamma}$, it can be seen that $\frac{\partial S W^{S G *}}{\partial \alpha}<0$

The proof is completed.

\section{References}

1. Drake, D.F.; Spinler, S. OM Forum-Sustainable Operations Management: An Enduring Stream or a Passing Fancy? Manuf. Serv. Oper. Manag. 2013, 15, 689-700. [CrossRef]

2. Colglazier, W. Sustainable development agenda: 2030. Science 2015, 349, 1048-1050. [CrossRef] [PubMed]

3. Griggs, D.; Stafford-Smith, M.; Gaffney, O. Policy: Sustainable development goals for people and planet. Nature 2013, 495, 305. [CrossRef]

4. Gong, Y.; Jia, F.; Brown, S.; Koh, L. Supply chain learning of sustainability in multi-tier supply chains: A resource orchestration perspective. Int. J. Oper. Prod. Manag. 2018, 38, 1061-1090. [CrossRef]

5. Zhai, Q.; Cao, H.; Zhao, X.; Yuan, C. Assessing application potential of clean energy supply for greenhouse gas emission mitigation: A case study on General Motors global manufacturing. J. Clean. Prod. 2014, 75, 11-19. [CrossRef]

6. Dong, C.; Shen, B.; Chow, P.S.; Yang, L.; Ng, C.T. Sustainability investment under cap-and-trade regulation. Ann. Oper. Res. 2016, 240, 1-23. [CrossRef]

7. China's Agenda 21 Group. China's Agenda 21-White Paper on China's Population, Environment, and Development in the 21st Century; China Environmental Science Press: Beijing, China, 1994.

8. Climent, F.; Soriano, P. Green and Good? The Investment Performance of US Environmental Mutual Funds. J. Bus. Ethics 2011, 103, 275-287. [CrossRef]

9. Rothenberg, S.; Pil, F.K.; Maxwell, J. Lean, green, and the quest for superior environmental performance. Prod. Oper. Manag. 2001, 10, 228-243. [CrossRef]

10. Green, K.; Morton, B.; New, S. Purchasing and environmental management: Interactions, policies and opportunities. Bus. Strategy Environ. 1996, 5, 188-197. [CrossRef]

11. Chirambo, D. Towards the achievement of SDG 7 in sub-Saharan Africa: Creating synergies between Power Africa, Sustainable Energy for All and climate finance in-order to achieve universal energy access before 2030. Renew. Sustain. Energy Rev. 2018, 94, 600-608. [CrossRef] 
12. Krass, D.; Nedorezov, T.; Ovchinnikov, A. Environmental taxes and the choice of green technology. Prod. Oper. Manag. 2013, 22, 1035-1055. [CrossRef]

13. Melnyk, S.A.; Smith, R.T. Green Manufacturing; Computer Automated Systems of the Society of Manufacturing Engineers: Southfield, MI, USA, 1996.

14. Shi, B. Green Supply Chain Management and Implementing Strategy. In Proceedings of the International Conference on Logistics Engineering and Supply, Nanjing, China, 19 November 2008; p. 85.

15. Zhou, M.; Pan, Y.; Chen, Z.; Yang, W.; Li, B. Selection and evaluation of green production strategies: Analytic and simulation models. J. Clean. Prod. 2012, 26, 9-17. [CrossRef]

16. Chen, C. Design for the Environment: A Quality-Based Model for Green Product Development. Manag. Sci. 2001, 47, 250-263. [CrossRef]

17. Hu, G.; Wang, L.; Chen, Y.; Bidanda, B. An oligopoly model to analyze the market and social welfare for green manufacturing industry. J. Clean. Prod. 2014, 85, 94-103. [CrossRef]

18. Albino, V.; Balice, A.; Dangelico, R.M. The effect of the adoption of environmental strategies on green product development: A study of companies on world sustainability indices. Int. J. Manag. 2012, 29, 525-538.

19. Liu, Z.; Anderson, T.D.; Cruz, J.M. Consumer environmental awareness and competition in two-stage supply chains. Eur. J. Oper. Res. 2012, 218, 602-613. [CrossRef]

20. Zhang, L.; Wang, J.; You, J. Consumer environmental awareness and channel coordination with two substitutable products. Eur. J. Oper. Res. 2015, 241, 63-73. [CrossRef]

21. Wang, Z.; Subramanian, N.; Gunasekaran, A.; Abdulrahman, M.D.; Liu, C. Composite sustainable manufacturing practice and performance framework: Chinese auto-parts suppliers' perspective. Int. J. Prod. Econ. 2015, 170, 219-233. [CrossRef]

22. Conrad, K. Price competition and product differentiation when consumers care for the environment. Environ. Resour. Econ. 2005, 31, 1-19. [CrossRef]

23. Sinayi, M.; Rasti-Barzoki, M. A game theoretic approach for pricing, greening, and social welfare policies in a supply chain with government intervention. J. Clean. Prod. 2018, 196, 1443-1458. [CrossRef]

24. Guo, D.; He, Y.; Wu, Y.; Xu, Q. Analysis of supply chain under different subsidy policies of the government. Sustainability 2016, 8, 1290. [CrossRef]

25. Sheu, J.B.; Chen, Y.J. Impact of government financial intervention on competition among green supply chains. Int. J. Prod. Econ. 2012, 138, 201-213. [CrossRef]

26. Hu, G. Market and social welfare analysis for hybrid sustainable manufacturing industry. Int. J. Sustain. Manuf. 2012, 2, 338-355. [CrossRef]

27. Zhou, Y.; Hu, F.; Zhou, Z. Pricing decisions and social welfare in a supply chain with multiple competing retailers and carbon tax policy. J. Clean. Prod. 2018, 190, 752-777. [CrossRef]

28. Guo, R.; Lee, H.L.; Swinney, R. Responsible sourcing in supply chains. Manag. Sci. 2015, 62, $2722-2744$. [CrossRef]

29. Rodriguez-Ibeas, R. Environmental product differentiation and environmental awareness. Environ. Resour. Econ. 2007, 36, 237-254. [CrossRef]

30. Iyer, G. Coordinating channels under price and nonprice competition. Mark. Sci. 1998, 17, 338-355. [CrossRef]

31. Hong, Z.; Guo, X. Green product supply chain contracts considering environmental responsibilities. Omega 2018, 28, 1-12. [CrossRef]

(C) 2019 by the authors. Licensee MDPI, Basel, Switzerland. This article is an open access article distributed under the terms and conditions of the Creative Commons Attribution (CC BY) license (http://creativecommons.org/licenses/by/4.0/). 